\title{
Core-scale radioscopic imaging: a new method reveals density-calcium link in Antarctic firn
}

\author{
Johannes FREITAG, Sepp KIPFSTUHL, Thomas LAEPPLE \\ Alfred Wegener Institute Helmholtz Centre for Polar and Marine Research, Bremerhaven, Germany \\ E-mail: johannes.freitag@awi.de
}

\begin{abstract}
A new radioscopic imaging technique has been developed to measure firn density in unprecedented resolution and accuracy even when the porosity is low or the geometry of a core or piece of core is not perfect. The technique is based on an X-ray microfocus computer tomograph (ICE-CT) designed especially for ice-core applications. Applied on an archive piece of the Antarctic firn core B32 drilled in Dronning Maud Land in 1998, the obtained density profile shows a strong correlation with the calcium ion concentration as found previously in Greenland. Given the impurity-density relationship found previously in Greenland, our result suggests both improved accuracy of the new density measurements and an impurity-density relationship with a similar magnitude in Greenland to that on the Antarctic plateau. Our measurements provide first evidence that the impurity-density relationship is a universal feature of polar firn and that the calcium ion concentration can serve as a proxy to describe quantitatively the effect of the impurities on densification.
\end{abstract}

\section{INTRODUCTION}

Models of firn densification play a key role in dating air inclusions in polar ice cores (EPICA Community Members, 2004). Current firn models are semi-empirical approaches (Herron and Langway, 1980; Barnola and others, 1991; Arnaud and others, 2000; Goujon and others, 2003) relying on measurements of the firn density. Firn density is most commonly measured by the volumetric method (VOL), calculating the density from the ratio of weight to volume. The uncertainty in density is $<1 \%$ when the method is applied to core segments of regular shape. The main disadvantage is the low vertical resolution of the order of a metre. A better vertical resolution on the millimetre scale has been achieved by gamma-ray absorption (GAM) in which the attenuation of a gamma-ray beam through a moving core is measured (Wilhelms, 1996). Similar results can be obtained by inverting dielectric measurements in terms of density and conductivity (Wilhelms, 2005). As these techniques rely on knowledge of core geometry, a regularshaped core without cracks and cuts is necessary to derive high-resolution density profiles. Recently, Hörhold and others (2011) systematically analysed high-resolution density profiles and observed an unexpected strong layering at the firn-ice transition at almost all polar sites. In a further study, Hörhold and others (2012) showed that the increase of density variations with depth is accompanied by an increasing correlation between density and the logarithm of the concentration of calcium ions $\left(\mathrm{Ca}^{2+}\right)$. Hörhold and others (2012) interpreted the relation between $\mathrm{Ca}^{2+}$ and density as an influence of impurities on the densification of snow to ice. This proposed impurity effect was based on measurements of two Greenland firn cores and three firn cores from Dronning Maud Land, Antarctica. Whereas the Greenland cores show a pronounced significant positive correlation between $\mathrm{Ca}^{2+}$ and density in deep firn of $\sim 0.6-$ 0.7 , the correlation in all Antarctic cores is less pronounced, with values of $\sim 0.3-0.4$ at maximum. The authors discussed different potential causes for the weaker correlation in the Antarctic firn cores, particularly observed at densities close to the density of ice. The reduced data quality is one cause that might result from difficulties of the gamma-ray method in measuring small-scale density variations at low porosity when the core quality is poor.

To overcome this problem, we developed an X-ray microfocus computer tomograph (ICE-CT) designed especially to measure density variations on samples of low porosity in high resolution and quality. The new imaging technique accounts for poor core geometry. The new method is applied to an archive piece of core B32 drilled in Antarctica at Kohnen station (EPICA Dronning Maud Land (EDML) site). Hörhold and others (2012) analysed the density data obtained by VOL and by gamma-ray absorption (GAM) during the austral summer 1997/98 (Oerter and others, 2000) on the full core. We show here that the correlation of density measured by the new technique and $\mathrm{Ca}^{2+}$ develops and increases with depth in comparable strength as previously observed only for Greenland firn cores.

\section{METHOD}

The radioscopic imaging is performed using an ICE-CT developed in cooperation with the Fraunhofer Institute EZRT (Development Centre for X-ray Technology) Fürth, Germany, and designed for ice-core applications with typical core dimensions of $10 \mathrm{~cm}$ diameter and $1 \mathrm{~m}$ length (Fig. 1). It is housed in a $3 \mathrm{~m} \times 3 \mathrm{~m} \times 3 \mathrm{~m}$ cold laboratory kept at a constant temperature of $-14.0 \pm 0.2^{\circ} \mathrm{C}$. The cold laboratory is placed in an X-ray protection chamber made of steel concrete and covered by lead plates. The X-ray source used is a Feinfocus-FXE-225 tube operated at acceleration voltages of $40-225 \mathrm{kV}$ and tube currents of up to $4000 \mu \mathrm{A}$. The tube shielded by a carbon-fibre housing is heated to $\sim 0^{\circ} \mathrm{C}$. A slit collimator is mounted directly at the front of the X-ray outlet and blocks the widely scattered part of the emitted radiation. The detector Xeye 4000 is $200 \mathrm{~mm} \times 400 \mathrm{~mm}$ in size and contains $4000 \times 8000$ pixels each of $50 \mu \mathrm{m}$ size. It is housed in a carbon-fibre box and is heated to $\sim 0^{\circ} \mathrm{C}$. Detector and tube are mounted on two vertically oriented air-buffered axes placed on a granite base. They can be moved upwards or downwards independently by $1 \mathrm{~m}$. 

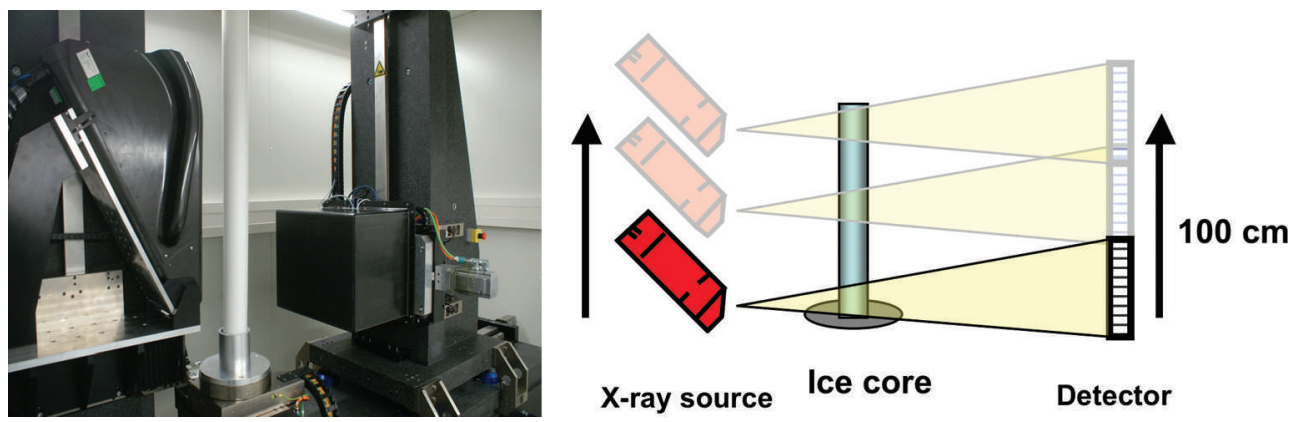

Fig. 1. Left: image of the ICE-CT inside the cold laboratory; right: a schematic view of the X2D scanning routine.

The horizontal distance between tube and detector can be varied between 0.1 and $1.1 \mathrm{~m}$. A turning table equipped with a carbon-fibre tube for keeping the ice cores in position is placed in between and mounted on a stage displaceable perpendicular to the beam direction.

Illuminating firn cores by X-rays and capturing the transmitted radiation results in greyscale-coded intensity images known as radioscopic images. Variations in grey values reflect variations in transmission caused by different travel distances through the ice matrix. We perform a twodimensional (X2D) scan of a firn core by recording a set of images during a synchronized movement of source and detector along the vertical axis and composing the centre lines from each image to one continuous core image (see Figs 4 and 6 further below). The scans are performed with fourfold magnification giving a field of view of $\sim 11 \mathrm{~cm}$ to cover the whole cross section of the core $(10 \mathrm{~cm})$ and the beam intensity in free air for later corrections of beam intensity variations. Tube voltage and current are set to $140 \mathrm{kV}$ and $300 \mu \mathrm{A}$, respectively. With an eightfold detector binning $(0.400 \mathrm{~mm})$, the spatial resolution is $0.12 \mathrm{~mm}$ per pixel and the exposure time for each image is $\sim 100 \mathrm{~ms}$. The vertical movement of source and detector is adjusted to the

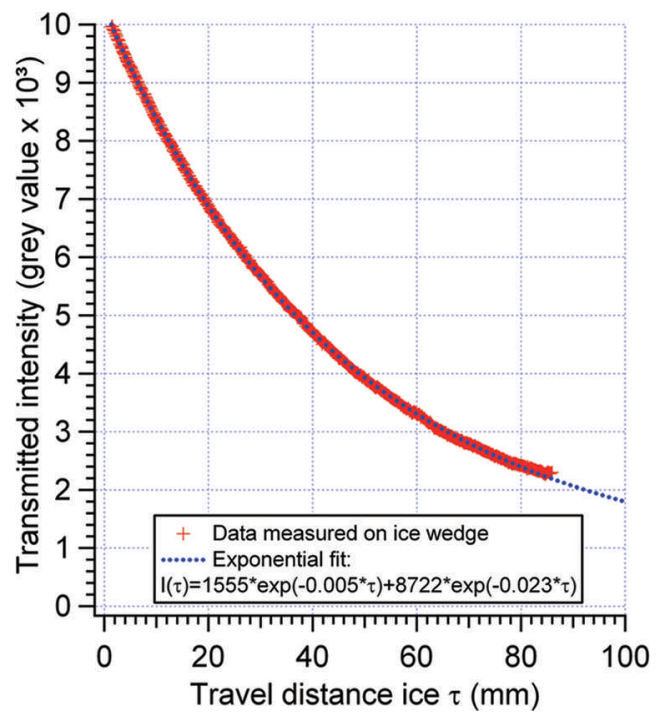

Fig. 2. Calibration curve (Eqn (1c)) derived from the measured transmission through a wedge of $86 \mathrm{~mm}$ side length made of pure bubble-free ice. The intensities are given in arbitrary grey-value units (a.u.). The curve fitting results in initial intensities $i_{\text {0soft }}=$ 8722 a.u. and $i_{\text {ohard }}=1555$ a.u. with attenuation coefficients $k_{\text {soft }}=$ $0.023 \mathrm{~mm}^{-1}$ and $k_{\text {hard }}=0.005 \mathrm{~mm}^{-1}$. exposure time to record $\sim 2000$ single images for scanning a core $1 \mathrm{~m}$ in length. The images are recorded on the fly without stopping the axis movement. An X2D scan of a $1 \mathrm{~m}$ core segment takes $\sim 3 \mathrm{~min}$.

The X-ray source used for the ICE-CT emits bremsstrahlung over a broad range of energies with an upper limit equal to the acceleration voltage of the source tube. The emitted intensity $I_{\mathrm{e}}$ is given as

$$
l_{\mathrm{e}}=\int_{0}^{E_{\max }} \frac{\mathrm{d} i_{\mathrm{e}}(E)}{\mathrm{d} E} \mathrm{~d} E
$$

with the spectral intensity $i_{\mathrm{e}}(E)$.

After passing the firn matrix, the transmitted intensity $I_{\mathrm{t}}$ of the beam can be described as function of the travel distance $\tau_{\text {ice }}$ based on the Beer-Lambert law. Because of the polychromatic character of the emitted beam (Eqn (1a)) $I_{\mathrm{t}}$ is expressed by

$$
I_{\mathrm{t}}\left(\tau_{\text {ice }}\right)=\int \frac{\mathrm{d} i_{\mathrm{e}}(E)}{\mathrm{d} E} \mathrm{e}^{-k_{\text {ice }}(E) \tau_{\text {ice }}} \mathrm{d} E
$$

with an attenuation coefficient $k_{\text {ice }}$ of ice dependent on the energy $E$ of the incoming radiation. $k_{\text {ice }}$ increases by about a factor of 5 with decreasing $E$ in the working range of the ICECT.

The polychromatic energy spectrum generated by the Xray tube is poorly known. Therefore the relationship between transmission and travel distance $l_{\mathrm{t}}\left(\tau_{\text {ice }}\right)$ of Eqn (1b) is determined empirically by measuring the transmitted $\mathrm{X}$-rays through a wedge of pure ice with known geometry and approximating the measurement as the sum of two exponential terms with different attenuation coefficients (Fig. 2):

$$
I\left(\tau_{\text {ice }}\right) \approx i_{0 \text { soft }} \mathrm{e}^{-k_{\text {soft }} \tau_{\text {ice }}}+i_{0 \text { hard }} \mathrm{e}^{-k_{\text {hard }} \tau_{\text {ice }}}
$$

The use of two different attenuation coefficients $\left(k_{\text {soft }}, k_{\text {hard }}\right)$ with different initial intensities $\left(i_{\text {Osoft }}\right.$ and $\left.i_{\text {Ohard }}\right)$ implements the beam-hardening effect well known in X-ray applications. The attenuation of low-energy photons (soft X-rays) is larger than that for high-energy photons (hard X-rays). The transformation of intensity data to travel distances is performed using the transfer function (Eqn (1c)) with parameters derived from the calibration shown in Figure 2. An example result of the calculated travel distances through a horizontal ice-core section is shown in Figure $3 \mathrm{~b}$. Before the conversion, the images are corrected for attenuation by the sample holder, for the geometrical distortion due to fan beam geometry of the X-ray emissions and for variations of initial intensity with time due to source tube instabilities. The spatial resolution in each horizon is calculated from the positions of the tube 
walls captured in the scan, which have a known distance of $100 \mathrm{~mm}$.

By assuming a cylindrical shape for the measured core samples and a homogeneous density in the horizontal plane, the profile of the travel distance $\tau_{\text {ice }}$ in a certain firn layer can be approximated by

$$
\tau_{\text {ice }}(x, z=\text { const })=2 n_{\text {ice }} \sqrt{r^{2}-(x-a)^{2}}
$$

with the relative density $n_{\text {ice }}$ defined as the portion of ice divided by the total volume and with radius $r$ and the centre coordinate $a$ of the cylindrical core in the $x$ direction.

For each layer of the ice core, $n_{\text {ice, }} r$ and $a$ are estimated by a least-squares fit of Eqn (2) to the measured travel distance (Fig. 3). If the measurements are performed on onethird of a full core then the curved profile is too short for fitting the radius properly. In this case the radius $r$ has to be fixed at a certain value before fitting and only $a$ and $n_{\text {ice }}$ can be derived from the fitting procedure. To reduce the noise, we fit Eqn (2) over nine rows and nine columns, which correspond to $\sim 1 \mathrm{~mm}^{2}$, the typical size of an ice grain. The results are not sensitive to this choice. The density profile $\rho(z)$ is calculated from $n_{\text {ice }}(z)$ by multiplying it by $0.919 \mathrm{~g} \mathrm{~cm}^{-3}$, which is the pure ice density $\rho_{\text {ice }}$ at the temperature of the cold laboratory $T=-14^{\circ} \mathrm{C}$

$$
\rho(z)=\left(1-n_{\text {pore }}\right) \rho_{\text {ice }}=n_{\text {ice }} \rho_{\text {ice }}
$$

where $n_{\text {pore }}$ is the porosity of the firn sample and describes the portion of air in the firn volume.

Outliers in the density profile, caused by breaks and large grooves in the core, are detected by analysing the residuals of the fit. Regions that show a residual larger than twice the median residual of the whole core segment are removed. This heuristic method was found to best mimic the visual detection of outliers. Similar results can be obtained with other criteria.

The core segments analysed here are the archive pieces of core B32 drilled in the austral field season 1997/98 in Dronning Maud Land, which were stored at $-25^{\circ} \mathrm{C}$ in Bremerhaven, Germany. The segments are cut vertically and consist mostly of about one-third of the cylindrical core. Before recording, the segments are rotated to bring the sectional areas of the truncated cores into line with the direction of illumination, seen as a sharp transition at the boundary between the core and surrounding air. Because of the long storage time ( $\sim 15$ years between coring and measurements) some pieces are slightly bent or warped. The density profiles of each piece are derived from the fitting procedure of Eqn (2) by assuming a fixed core radius of $49 \mathrm{~mm}$ over the whole depth profile (Figs 4-6). Samples from one core box with $6 \mathrm{~m}$ of firn had problems with the depth assignments. Therefore they are excluded from the correlation analysis between density and $\mathrm{Ca}^{2+}$ shown in Figure 7 .

\section{RESULTS AND DISCUSSION}

The travel-distance profiles derived from the $\mathrm{X} 2 \mathrm{D}$ images exhibit the expected cylindrical shape that is imposed by the cross-sectional geometry of the firn core (Fig. 3). The general curve pattern is overprinted by undulations on the millimetre scale. These fluctuations are small compared with the general trend. The undulations in the profiles are mainly due to the coarse firn structure and the heterogeneous distribution of the ice phase in the firn matrix and are largest

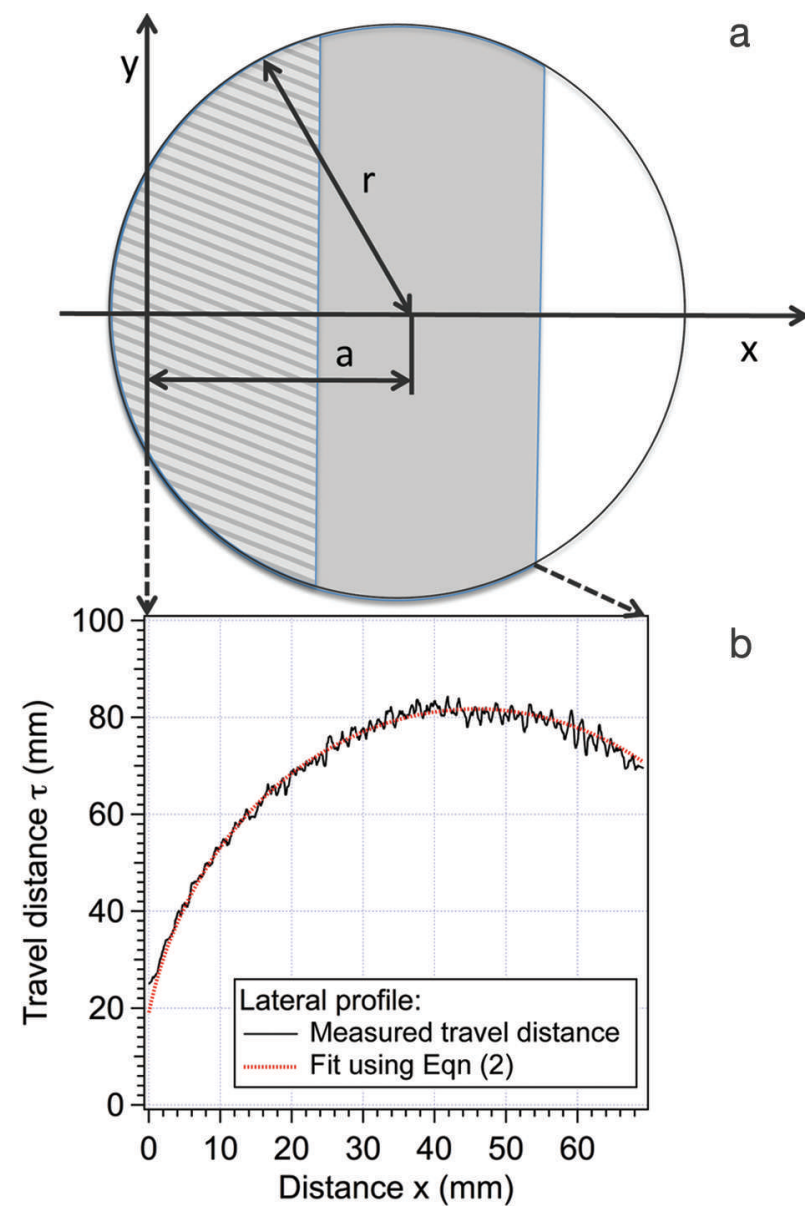

Fig. 3. (a) Scheme of a horizontal cross section through an ice-core segment illustrating the definition of the centre offset $a$ and radius $r$ in the frame of reference. $y$ denotes the direction of the X-ray beam. The grey and grey-shaded areas show the maximum and minimum size of the archive pieces of B32 measured in this study. (b) An example of a calculated travel distance profile. The dotted curve is the fit using Eqn (2). The derived parameters are $a=47 \mathrm{~mm}$ and $n_{\text {ice }}=0.79$. The core radius $r$ was fixed to $49 \mathrm{~mm}$.

in the upper firn column, which exhibits high porosities and large grains.

Overall, the mean density measured by $\mathrm{X} 2 \mathrm{D}$ (this study) is in good agreement with VOL and GAM (Fig. 5). The VOL density tends to be slightly lower than GAM and X2D, which might be due to the fact that the VOL method underestimates density when core segments exhibit large grooves or cracks. The density variability shows a similar evolution with depth, but generally less variability using the X2D method as the noise level is smaller.

The uncertainty in the $\mathrm{X} 2 \mathrm{D}$-derived density results from uncertainties in the correction and calibration procedure for the grey-value images and from the fitting procedure. The fitting procedure assumes a laterally homogeneous density, as well as a circular core geometry. The first assumption is valid for most of the core segments. Tilted layer boundaries are observed in $<5 \%$ of the ice volume and are restricted to the upper firn column with inclinations usually $<10^{\circ}$. The main error for the estimates of the absolute density values results from the uncertainty in either the specification of a core radius $r$ or if the core radius is determined as a free parameter in the estimation uncertainty of the parameter. Deviations in the core radius of $1 \mathrm{~mm}$ change the mean 


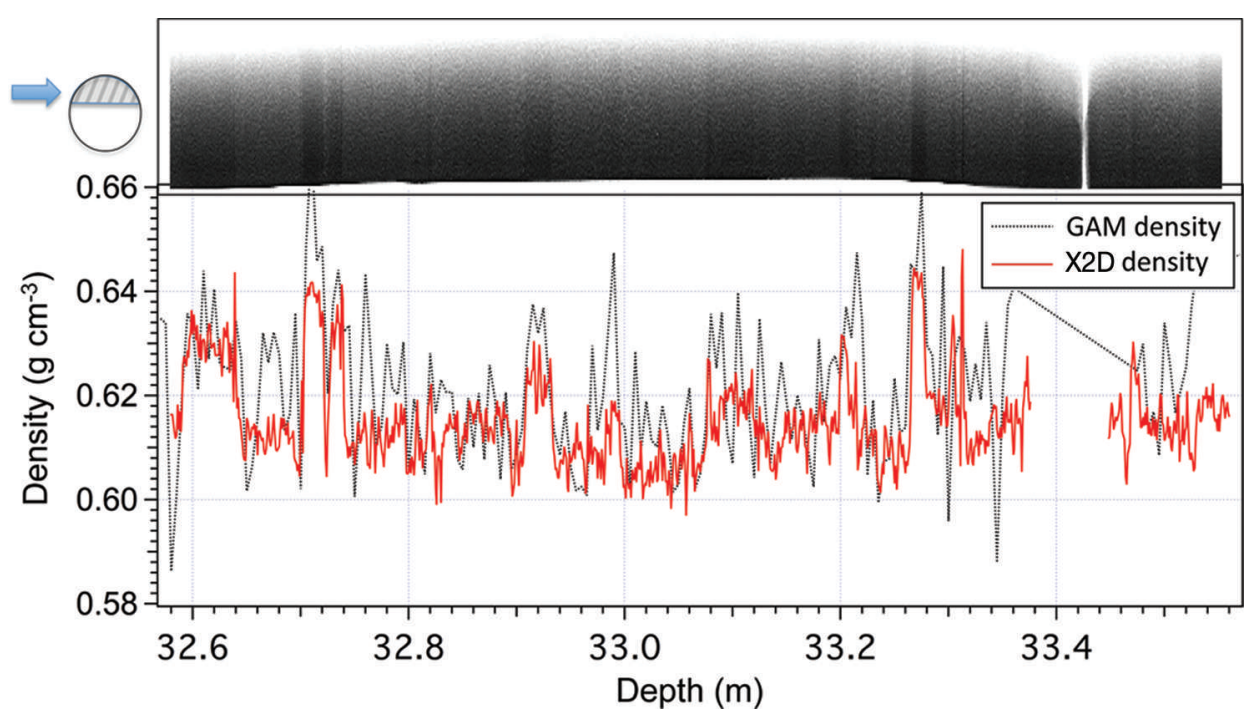

Fig. 4. Top: X2D scan of a $1 \mathrm{~m}$ long core segment of B32 bag33 (32-33 m depth); bottom: comparison of the X2D density profile (red line) and the gamma density (grey line) profile (Hörhold and others, 2011). The X2D density shows a step-like behaviour in accordance with the layering visible as banding in the grey-value image. Thin layers (e.g. wind crusts) are detected as positive peaks in density. The gamma density follows the general trend but exhibits larger scattering and does not resolve all crusts or even broader layers of density.

density by $\sim 0.01 \mathrm{~g} \mathrm{~cm}^{-3}$. If half the core or a larger piece is available, the core radius is well determined by the greyscale image and can be estimated from the intensity data. For smaller sample pieces, which is the case for the $\sim 30 \%$ core segment of $\mathrm{B} 32$, the radius is not well determined. In this case, assuming a fixed radius and centre offset results in a smaller density error even if the true radius might not be constant, especially in the upper metres of the firn cores. If the radius is known, the density estimates remain stable even for sample volumes $<20 \%$ of a cylinder. As the core radius is constant across core pieces, the smallscale density variations measured in B32 are not affected by the limited sample volumes. This is supported by the comparison with GAM densities (Figs 4 and 5) and in the comparison with $\mathrm{Ca}^{2+}$ in the same core, which we show below. Despite the limited sample volumes, the B32 bag mean densities using the X2D, GAM and volumetric method are very similar (Fig. 5a). The evolution of the density variability with depth of X2D and GAM shows a similar behaviour but shows generally less variability using the X2D method, caused by the lower noise level of this method. This is especially true for the low-porosity regions at $60-80 \mathrm{~m}$ depth just above the firn-ice transition (Fig. 5b). The minimum variability of $\sim 0.01 \mathrm{~g} \mathrm{~cm}^{-3}$ (1SD) around 20$30 \mathrm{~m}$ depth suggests a noise level for the X2D method smaller than this value.

The X2D measurements provide images of firn stratification. The stratification is imprinted as density variations down to the firn-ice transition at $\sim 90 \mathrm{~m}$ depth. The banding in deep firn is much clearer than previously suggested from GAM measurements, and fine structures not visible in the GAM measurements (e.g. crust-like layers, which can be identified down to the firn-ice transition) become visible (Fig. 6).
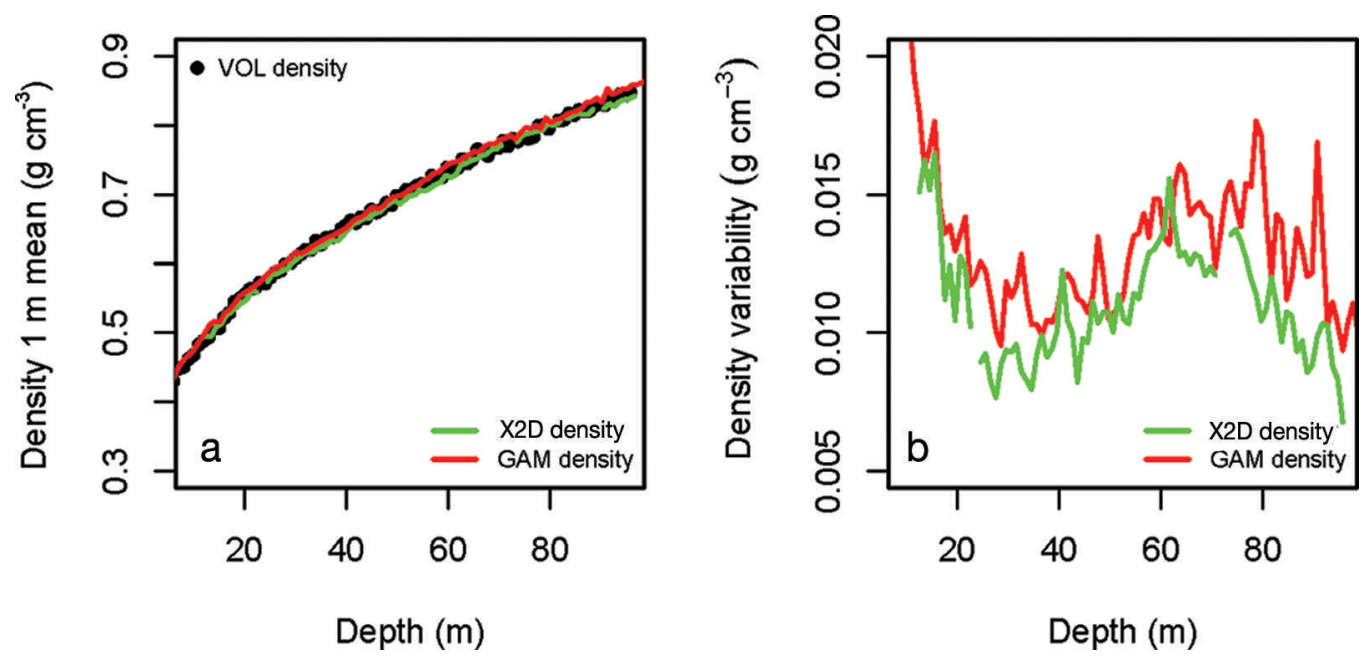

Fig. 5. Comparison of B32 mean density and density variability measured with different methods. (a) Bag mean density ( $1 \mathrm{~m}$ intervals) using the volumetric method (VOL), gamma-ray absorption (GAM) and the X2D technique. (b) Density variability (standard deviation over a $2 \mathrm{~m}$ running mean) using GAM and X2D density. 


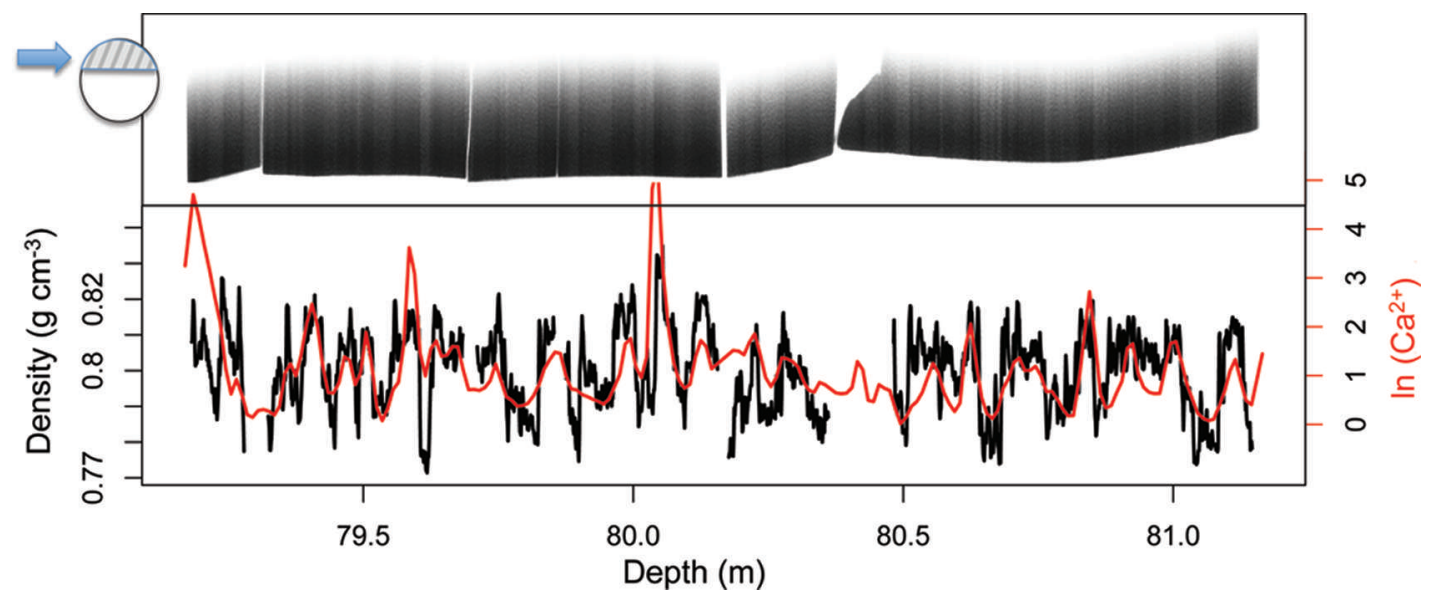

Fig. 6. Small-scale comparison of $\ln \left(\mathrm{Ca}^{2+}\right)$ and $X 2 \mathrm{D}$ density around the firn-ice transition along with an X2D scan (upper panel).

In order to examine the relationship between the new X2D density data and the $\mathrm{Ca}^{2+}$ ion concentration previously presented by Hörhold and others (2012) we compare specific depth intervals visually (Fig. 6) and calculate the depth-dependent correlation between both datasets (Fig. 7). In the deep firn column, small-scale density variations strongly follow the profile of the logarithm of $\mathrm{Ca}^{2+}$ concentrations. To avoid artefacts caused by potential changes in the core diameter and the corresponding density jumps, the correlation between $\mathrm{Ca}^{2+}$ and $\mathrm{X} 2 \mathrm{D}$ density is calculated separately on every continuous piece of ice $>30 \mathrm{~cm}$ long. The running mean over $4 \mathrm{~m}$ is shown, to investigate the development of correlation with depth (Fig. 7).

The correlation increases with depth from zero to values $>0.6$. It is remarkable that this high correlation persists throughout the firn-ice transition. To compare the new results with the previous study of Hörhold and others (2012) based on GAM densities, we recalculate the GAM density to
$\mathrm{Ca}^{2+}$ correlation applying the same criteria as for the X2D correlation. This leads to a higher correlation than reported by Hörhold and others (2012), as breaks and bag cuts are removed (Fig. 7, dotted and solid red lines), but still the correlation using the GAM densities is much lower and less stable at depths below $25 \mathrm{~m}$. The high correlation with $\mathrm{Ca}^{2+}$ in deep firn obtained by X2D is interpreted as strong support for the quality of the X2D density data in order to accurately detect small-scale variations. The development of the density- $\mathrm{Ca}^{2+}$ correlation with increasing depth is similar to that found for Greenlandic sites (Hörhold and others, 2012). Following Hörhold and others (2012) we interpret the increase in correlation as evidence of an impurity-controlled firn densification. Layers of higher impurity load densify faster than layers of low impurity load, leading to a synchronization of density with the impurity load in the deeper firn. The similar behaviour found in the Antarctic B32 and Greenland firn cores is surprising, as conditions in

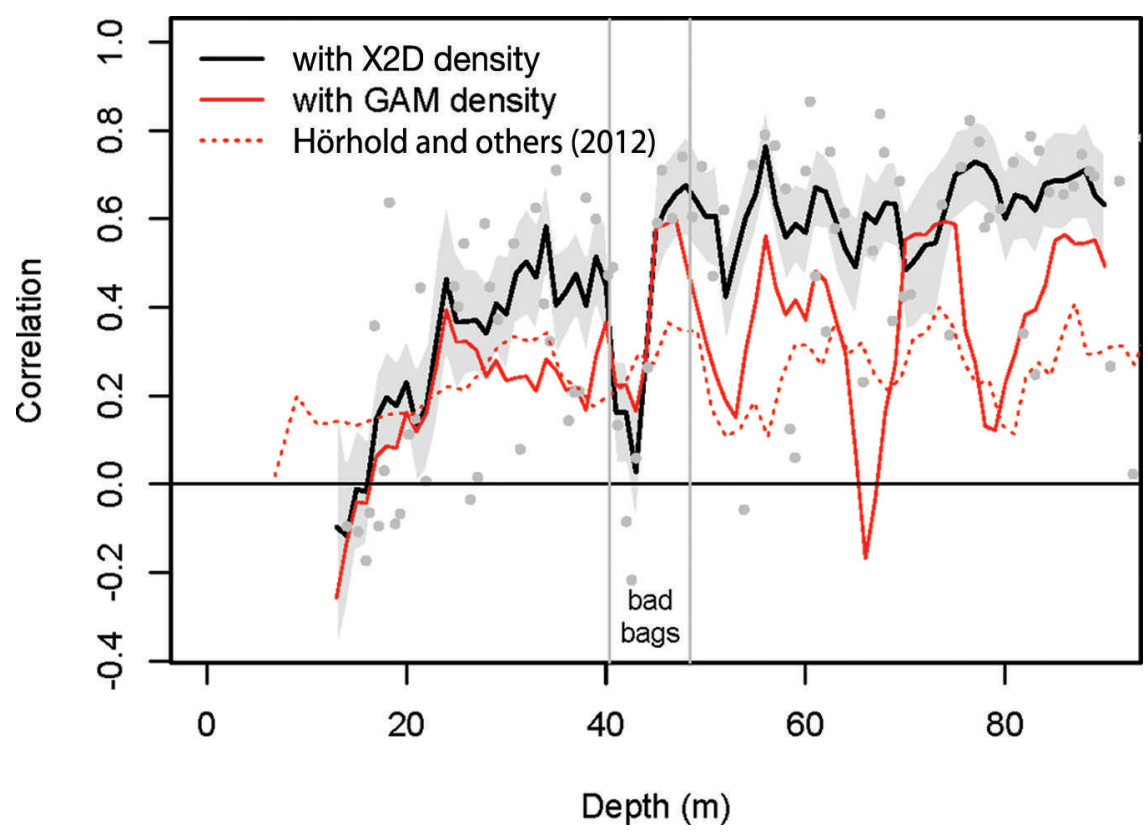

Fig. 7. Evolution of $\ln \left(\mathrm{Ca}^{2+}\right)$ with X2D density correlation with depth. The correlation is calculated separately over intact single core pieces (grey dots). Additionally, the $4 \mathrm{~m}$ running mean of the single correlations (black solid line) and its uncertainty (grey bar, 1SD) are shown. The correlation, calculated using the same method as with the GAM density (red solid line), is smaller and less stable. As reference, the correlation using the method from Hörhold and others (2012) is shown as a red dotted line. 
the two polar regions are very different. The modern $\mathrm{Ca}^{2+}$ ion concentration at B32 is $<5 \mathrm{ng} \mathrm{g}^{-1}$, i.e. about one-tenth of that at Greenlandic sites. Further, the sources of $\mathrm{Ca}^{2+}$ are different: on the Antarctic plateau the non-sea-salt fraction of the $\mathrm{Ca}^{2+}$ concentration is $\sim 50 \%$, whereas in Greenland the $\mathrm{Ca}^{2+}$ records are dominated by dust input.

\section{SUMMARY AND CONCLUSION}

We have presented a new method for high-quality measurements of firn density in high resolution by using a radioscopic imaging technique. The new method has been applied on archive pieces of the Antarctic firn core B32 and compared with results obtained by the gamma method on the full core. Both methods reveal a similar evolution of the mean density. However, the new method allows a much higher resolution and lower noise level. It resolves more details than the gamma measurements, especially in the low-porosity region where the air is entrapped in ice.

Despite the fact that only an archive piece (mostly only one-third of the full core) was available for this study and the quality of the analysed core material was often poor, realistic relative density variations, including the layering in the deep firn, became visible. We expect that with better core material the absolute and relative density variability of firn can be determined with high accuracy. This will allow new insights into the processes controlling densification of polar firn in general and into the structure of the firn-ice transition and pore close-off in particular.

$\mathrm{Ca}^{2+}$ ion concentration and density show a strong correlation increasing with depth, which even persists across the firn-ice transition. This behaviour is similar to the findings in Greenland. While the result confirms the impurity effect on densification, it is also surprising because the $\mathrm{Ca}^{2+}$ concentration and source, as well as the climatic conditions like accumulation and temperature, differ considerably on the two ice sheets.

The revised density profile for B32 measured by radioscopic imaging is the first evidence of this impurity effect acting in the firn on the Antarctic plateau. The $\mathrm{Ca}^{2+}$ ion concentration seems also to be a reliable proxy for the impurity effect on densification under Antarctic conditions.

\section{ACKNOWLEDGEMENTS}

We thank Maria Seifert and Robin Beer for support of the X2D measurements, and Michael Salamon and Virginia Voland from Fraunhofer EZRT for keeping the ICE-CT and software analysis running. T. Laepple was supported by the Daimler and Benz Foundation.

\section{REFERENCES}

Arnaud L, Barnola JM and Duval P (2000) Physical modeling of the densification of snow/firn and ice in the upper part of polar ice sheets. In Hondoh T ed. Physics of ice core records. Hokkaido University Press, Sapporo, 285-305

Barnola JM, Pimienta P, Raynaud D and Korotkevich Y (1991) $\mathrm{CO}_{2-}$ climate relationship as deduced from the Vostok ice core: a reexamination based on new measurements and on a re-evaluation of the air dating. Tellus B, 43(2), 83-90 (doi: 10.1034/ j.1600-0889.1991.t01-1-00002.x)

EPICA Community Members (2004) Eight glacial cycles from an Antarctic ice core. Nature, 429(6992), 623-628 (doi: 10.1038/ nature02599)

Goujon C, Barnola JM and Ritz C (2003) Modeling the densification of polar firn including heat diffusion: application to close-off characteristics and gas isotopic fractionation for Antarctica and Greenland sites. J. Geophys. Res., 108(D24), 4792 (doi: 10.1029/2002JD003319)

Herron MM and Langway CC, Jr (1980) Firn densification: an empirical model. J. Glaciol., 25(93), 373-385

Hörhold MW, Kipfstuhl S, Wilhelms F, Freitag J and Frenzel A (2011) The densification of layered polar firn. J. Geophys. Res., 116(F1), F01001 (doi: 10.1029/2009JF001630)

Hörhold MW, Laepple T, Freitag J, Bigler M, Fischer $\mathrm{H}$ and Kipfstuhl S (2012) On the impact of impurities on the densification of polar firn. Earth Planet. Sci. Lett., 325-326, 93-99 (doi: 10.1016/j.epsl.2011.12.022)

Oerter H and 6 others (2000) Accumulation rates in Dronning Maud Land, Antarctica, as revealed by dielectric-profiling measurements of shallow firn cores. Ann. Glaciol., 30, 27-34 (doi: 10.3189/172756400781820705)

Wilhelms F (1996) Leitfähigkeits- und Dichtemessung an Eisbohrkernen. Ber. Polarforsch/Rep. Pol. Res. 191.

Wilhelms F (2005) Explaining the dielectric properties of firn as a density-and-conductivity mixed permittivity (DECOMP). Geophys. Res. Lett., 32(16), L16501 (doi: 10.1029/2005GL022808) 